\title{
Bolivia: Apuntes para comprender la caída del gobierno del MAS más allá de la polarización
}

\section{Bolivia:Notes to understand the fall of the MAS government beyond polarization}

\section{Rocio Estremadoiro Rioja (iD}

Universidad Mayor de San Simón

roestremadoiro@gmail.com

\section{Resumen}

Este artículo busca examinar algunos aspectos que permiten comprender la caida del gobierno del MAS en noviembre de 2019, las características de la movilización que lo depuso y algunas pautas del gobierno que lo sucede. Ello, a partir de un trasfondo que procura alejarse de las interpretaciones maniqueas y polarizadas de quienes pugnan por el poder.

Palabras clave: Gobiernos del MAS, rupturas, crisis, régimen de transición.

\section{Summary}

This article seeks to examine some aspects permitting to understand that downfall of the government of MAS in November 2019, the characteristics of the people's mobilization that deposed it, and of the regime that followed. From a background trying to detach from Manichean and polarized interpretations of those trying to get political power.

Keywords: MAS's governments, ruptures, crises, transitional government.

Articulo: Recibido el 10 de junio de 2020 y aprobado el 26 de junio de 2020.

\section{Cómo citar este artículo:}

Estremadoiro, R. (2020). Bolivia: Apuntes para comprender la caída del gobierno del MAS más allá de la polarización. Reflexión política 22(45), pp. 30-43. doi: https://doi.org/10.29375/01240781.3637

\section{Introducción}

Después de catorce años de gobiernos sucesivos y de una hegemonía partidaria que parecía invencible a la cabeza del Movimiento al Socialismo (MAS), el 10 de noviembre de 2019 Evo Morales presentaba públicamente su renuncia luego de varias semanas de movilizaciones por un supuesto fraude que habría ocurrido en las elecciones del 20 de octubre de ese año y que le daban la victoria al MAS en primera vuelta.

Este desenlace suele ser interpretado desde dos polos: para los militantes, simpatizantes del MAS y principales líderes, la renuncia del presidente fue motivada por presiones principalmente de los aparatos represivos del Estado encarnados en las Fuerzas Armadas (FF.AA.) y la policía, ya que, en el primer caso, su máximo comandante, le "sugirió" al mandatario su renuncia y, en el segundo caso, la policía se había 
amotinado contra el Gobierno en varias regiones del país sumándose a las protestas civiles. Por tanto, al amparo de esos argumentos, habría ocurrido un golpe de Estado cívico-policial-militar.

En cambio, para la oposición partidaria al gobierno del MAS y para los heterogéneos sectores que se movilizaron en contra del resultado eleccionario, lo ocurrido fue consecuencia de la presión de las movilizaciones ciudadanas que protestaban contra la continuidad en el poder del MAS a través de lo que concibieron como un fraude electoral.

Esta dicotomía de percepciones tiende a manifestarse en consignas vacías que, luego de la salida de Evo Morales y la asunción del gobierno transitorio, por otros tantos días enfrentaron a Bolivia con episodios de violencia. Meses después, está latente el preocupante enfrentamiento que tiene como trasfondo la pugna por el poder entre el MAS, los partidos políticos opositores y los representantes del Gobierno transitorio. Por otra parte, esos maniqueísmos no son capaces de abordar e interpretar el panorama complejo que llevó al corolario de noviembre de 2019.

Por ello, este artículo ofrece pautas para el análisis de algunos factores que se configuraron en relación con la caída abrupta de los gobiernos del MAS, las particularidades de las movilizaciones en su contra y ciertas características del Gobierno transitorio en el marco de la delicada situación política y social que viene atravesando Bolivia.

\section{El poder y la caida: la pérdida de hegemonia ${ }^{1}$ del MAS}

\subsection{Contradicciones y rupturas}

Al remitirnos a la hegemonía partidaria del MAS, necesariamente habría que observar en el espejo circular del pasado y recordar lo que aconteció con la hegemonía del Movimiento Nacionalista Revolucionario (MNR) (1952-1964), o el caso de México, con la hegemonía del Partido Revolucionario Institucional (PRI) (1920-2000), instrumento partidario que tuvo la capacidad de modular tal maquinaria de poder que subyugó el sistema político mexicano por ocho décadas.

Las similitudes entre los tres partidos mencionados tienen que ver con un trasfondo de formaciones sociales complejas y étnicamente diversas, lo que resultó en una estructura partidaria que albergaba una amalgama de sectores que no necesariamente reflejaban una sola y compacta ideología, como los clásicos partidos leninistas. Al contrario, su éxito electoral puede explicarse por la flexibilidad ideológica que se materializaba en alianzas con grupos heterogéneos y que se acomodaba a las coyunturas políticas. Consecuentemente, el PRI, el MNR y el MAS fueron hegemónicos o predominantes en el sistema de partidos por largo tiempo, ganando con mayoría absoluta e igualmente controlando niveles territoriales intermedios y locales ${ }^{2}$.

A la par, la asunción al poder de dichas fuerzas políticas se generó después de una contundente ruptura social: en dos casos hubo una revolución y, en el otro, la antesala era una crisis social que depuso a un gobierno. Por ello, los tres partidos, fueron blanco de esperanzas de transformación, ganando elecciones y ejerciendo hegemonía partidaria por varias gestiones.

El caso del PRI es ilustrativo en esos aspectos. Dicho ente fue producto de la Revolución Mexicana de 1910, una revolución determinante en la alforja de las utopías más queridas de América Latina. Al procurar "institucionalizarla", se configuró el PRI. Entre las características de los sucesivos gobiernos del

${ }^{1}$ El concepto de hegemonía se puede definir como la suma de la dirección política de un grupo social acoplada a una "dirección intelectual y moral". Para Gramsci y sus contemporáneos, la hegemonía ocurre cuando la ideología de un grupo social logra extenderse a toda la sociedad o a varios sectores a través de la universalización de sus intereses, convirtiéndose así en hegemónica, o sea en una dirección no sólo política, sino intelectual y moral. Citas de Mouffe, 1988: 134. También el concepto alude a la hegemonía partidaria en el sentido de mantenerse como partido hegemónico o predominante (ganar elecciones con mayoría absoluta) dentro del sistema de partidos por mucho tiempo. Aquello suele estar relacionado con la definición anterior. En ese sentido, por un tiempo considerable, el MAS pudo articular los objetivos e intereses de varios grupos y las simpatías de no pocos sectores de la población, ejerciendo una dirección "intelectual y moral", lo que se confirmó en tres periodos gubernamentales en los que ganó por mayoría absoluta. Esta hegemonía se fue resquebrajando como se comenta en las líneas que siguen.

${ }^{2}$ Sobre el MNR, la amalgama ideológica y el pragmatismo que representaba es muy interesante el trabajo de Antezana, 1983. 
PRI ha resaltado su pragmatismo para mantener el poder, transcurriendo entre postulados ideológicos distintos, según la conveniencia y la coyuntura. Por ejemplo, mientras en las décadas de los 60 y 70 nuestros países franqueaban la sombra de las dictaduras militares, en México se seguía el "normal" cauce constitucional dominado por el PRI, pero esto no impidió que la "Doctrina de Seguridad Nacional" dejara su huella. Eso se evidenció en 1968, cuando las fuerzas gubernamentales masacraron a universitarios en Tlatelolco. Por ello, la hegemonía del PRI fue calificada como "dictadura perfecta"3: no tuvo la necesidad de apelar a los cuartelazos para regir con tintes casi absolutistas.

$\mathrm{Si}$ analizamos las gestiones del MAS, existieron pretensiones análogas para controlar el total del armazón estatal. Fue recurrente el intento de captación y control de varios organismos del Estado como el Poder Judicial, las FF.AA., la Defensoría del Pueblo, etc., sin contar la estrategia que se maquinó para que la mayor parte de los ámbitos territoriales intermedios y locales "autonómicos" fueran manejados por el partido predominante. Al tiempo, las organizaciones civiles como: sindicatos, gremios, movimientos sociales, entidades indígenas, etc., se vieron constantemente intervenidas, cooptadas, divididas ${ }^{4}$.

Asimismo, las tentativas de cooptar para fines partidarios las instituciones del Estado incluían una administración de justicia que era muy eficiente para escarmentar disidencias ${ }^{5}$, mientras se dejaba en impunidad a militantes partidarios del MAS que incurrieron en delitos ${ }^{6}$. Indistintamente se dio la desestructuración, funcionalización, debilitamiento y división de organizaciones sociales, indígenas, campesinas, etc., por parte del partido hegemónico para hacerlas serviles al gobierno. Fue el caso de la Central Obrera Boliviana (COB),
Confederación de Pueblos Indígenas de Bolivia (CIDOB), Consejo Nacional de Ayllus y Markas del Gullasuyo (CONAMAQ), entre otras organizaciones ${ }^{7}$.

Uno de los hechos más relevantes al respecto se refirió a la escisión del "Pacto de Unidad", o de los sectores sociales que, al iniciar el llamado "proceso de cambio", fueron su principal base social y donde estaban incluidos CIDOB y CONAMAQ, que, por motivos que trataremos enseguida, rompieron con el MAS. Como contraparte, el gobierno gestionó la creación y fortalecimiento de la Coordinadora Nacional por el Cambio (CONALCAM) como nuevo organismo social de sustento y compuesto por la Confederación Sindical Única de Trabajadores Campesinos de Bolivia (CSUTCB), la Confederación Sindical de Colonizadores de Bolivia (CSCB) y la Confederación Nacional de Mujeres Campesinas Indígenas Originarias Bartolina Sisa (CNMCIO-BS), además del apoyo militante e incondicional de las Federaciones del Trópico de campesinos cocaleros.

La ruptura del "Pacto de Unidad" fue la causa más significativa, entre varias, para el fraccionamiento del MAS como partido hegemónico. También se señala el alejamiento de sectores ambientalistas, indigenistas y de izquierda (clases medias e intelectuales) y un ahondamiento de diferencias con la COB. Cabe anotar que estos grupos veían en el MAS una opción histórica frente a los "partidos tradicionales" y la política en general, calificada como históricamente excluyente.

Se nominarán algunos acontecimientos que socavaron la legitimidad de los gobiernos del MAS como entes de transformación:

\subsubsection{La persistencia de la matriz extractivista y los imaginarios desarrollistas tradicionales}

Fue evidente la persistencia de la matriz extractivista y los imaginarios desarrollistas tradicionales

${ }^{3}$ En 1990 se llevó a cabo el "Encuentro Vuelta: La experiencia de la libertad" con varios importantes pensadores latinoamericanos, entre ellos Octavio Paz y Mario Vargas Llosa. En los pormenores de ese evento, en un programa de televisión, Vargas Llosa se refirió a los gobiernos del PRI como la "dictadura perfecta": "México es la dictadura perfecta. La dictadura perfecta no es el comunismo. No es la URSS. No es Fidel Castro. La dictadura perfecta es México. (...) Es la dictadura camuflada. (...) Tiene las características de la dictadura: la permanencia, no de un hombre, pero sí de un partido. Y de un partido que es inamovible" (Krauze, 2012) Más detalles en un artículo de Enrique Krauze, quien era el que conducía el programa de TV. En el mismo artículo, Krauze comentó que Octavio Paz se sintió incómodo con esa afirmación, pero que años antes había indicado que "en México no hay más dictadura que la del PRI y no hay más peligro de anarquía que el que provoca la antinatural prolongación de su monopolio político". También ver: El país, 1990. Más detalles sobre los gobiernos del PRI en: Knight, 2011, Knight, 2015 y Magaloni, 2016.

${ }^{4} \mathrm{Si}$ bien para respaldar estas acepciones se puede recurrir a fuentes primarias como noticias, también se puede revisar: Almaraz et al., 2012 y Rivera, 2015.

${ }^{5}$ En ese sentido, es innegable el abuso de poder a los que han sido sometidos José María Bacovic, el ex Magistrado Gualberto Cusi, Leopoldo Fernández, Gary Prado, entre otros. Ni qué decir del caso "terrorismo", cuando se acusó a un grupo de extranjeros de liderar una guerrilla separatista organizada por la oposición que, en ese momento, estaba liderada por algunos personajes de la burguesía cruceña. Por ejemplo, ver: Pomacahua, 2017, Página Siete, 2013 y Medrano, 2015. Más allá de las responsabilidades de estas personas en los delitos por los que fueron acusadas, todo ciudadano debería tener derecho a la presunción de inocencia y a un proceso transparente, equitativo, recto y justo. En estos casos, salta a la vista que no se han cumplido esas mínimas garantías y derechos.

'Uno de los más sonados hechos de corrupción fue el llamado "caso Fondo Indígena" que involucraba a ministros de ese gobierno. Ver: López, 2017. Otro ejemplo muy preocupante fue la violación a una trabajadora de limpieza por un Asambleísta de Chuquisaca de las filas del MAS en plena oficina pública, lo que fue registrado por las cámaras de seguridad. El delito que aún sigue impune. Revisar BBC, 2013.

${ }^{7}$ Ver nota 5 
en varios de los principales proyectos que han caracterizado a las gestiones gubernamentales lideradas por el MAS. Proyectos como las represas hidroeléctricas "El Bala" o "Rosita", el deseo de construir una planta nuclear, los proyectos relacionados con el Mutún, la continuidad de la explotación minera e hidrocarburífera como base de la economía boliviana, las "mega obras" o "mega carreteras" que no contemplaron de manera oportuna el impacto ambiental que conllevaban $\mathrm{y}$ que incluso vulneraron áreas protegidas $\mathrm{y}$ territorios indígenas, son una muestra de esa realidad ineludible.

Sobre ello, el suceso más relevante fue el empecinamiento gobiernista en la construcción de una carretera que atravesara el Territorio Indígena y Parque Nacional Isiboro Sécure (TIPNIS), lo que incluyó la represión de indígenas en la localidad de Chaparina cuando estos realizaban una marcha contra la carretera en septiembre de 2011. Este acontecimiento encarnó uno de los clivajes más cruciales en la legitimidad del MAS, porque implicó el alejamiento de la CIDOB, CONAMAQ y otras organizaciones étnicas e incluso autoridades y militantes del partido.

Otro indicador fueron los terribles incendios forestales en la zona de la Chiquitanía en 2019, como trasfondo de impunes chaqueos ${ }^{8}$ con fines agroindustriales, sectores que eran aliados del gobierno. El régimen no sólo respondió tardía y escuetamente, sino que minimizó el problema ${ }^{9}$.

\subsubsection{El culto a lo militar y la alianza con sectores conservadores}

Cuando se enarboló el llamado "proceso de cambio", una de las características de la retórica de sus principales líderes era la condena al pasado político boliviano con una crítica muy fuerte a las dictaduras militares de los 60 y los 70, y a la intervención de las FF.AA. como una especie de "partido político armado" durante ese luctuoso tiempo y gran parte de la historia del país.

Empero, en cuanto a la praxis gubernamental, no solamente se sepultó el sueño de vía hacia una nueva Constitución, y la implementación del Servicio Militar Voluntario, sino que se consolidó su obligatoriedad a través de una campaña promovida y defendida por el mismo Presidente Evo Morales.

Esto vino acompañado de una especie de nueva alianza del gobierno con las FF.AA. que significó que se mantuvieran los privilegios de los jerarcas de las mismas y fue incluso un obstáculo para el esclarecimiento de las responsabilidades por la violación de derechos humanos durante las dictaduras: los familiares de las víctimas de los regímenes militares trajinaron sin hallar justicia durante los periodos del MAS ${ }^{10}$.

Paradójicamente, eso no evitó que las FF.AA. se sumaran a las movilizaciones que culminaron con la renuncia de Evo Morales el 2019.

\subsubsection{Persistencia de ideologias conservadoras en materia de derechos de las mujeres, sexuales $y$ reproductivos}

Si bien es valedero que se han generado algunos avances en la legislación sobre estos temas bajo la administración del MAS, es ineludible el hecho de que, en el seno mismo de la Asamblea Constituyente, no haya habido discusión suficiente respecto a la inclusión en la nueva Constitución de derechos sexuales y reproductivos que fueron colocados en el tapete de la deliberación, pero que, en la fase de redacción de la Carta Magna, no fueron considerados ${ }^{11}$

Por otra parte, en lo que respecta a los derechos de las mujeres, a pesar de los aciertos en materia legislativa o en mecanismos de acción positiva para asegurar la participación femenina en la toma de decisiones, estos logros se vieron opacados por los recurrentes "chistes" o expresiones de las principales autoridades que denigraban a las mujeres ${ }^{12}$.

Lo preocupante, como ya se mencionó, es que hubo casos de agresiones sexuales a mujeres por funcionarios de gobierno en los que no existió voluntad política suficiente para esclarecer y escarmentar.

\footnotetext{
${ }^{8}$ Quema de bosques con fines agrícolas o agroindustriales.

${ }^{9}$ Revisar Página siete, 2019; Carrasco, 2019.

${ }^{10}$ En el 2010 el presidente Morales aseguró que no existían archivos clasificados que dieran luces de los desaparecidos en las dictaduras, reclamo por el que peregrinan hace décadas los familiares de los vulnerados. Lo que es peor, el presidente desvinculó a las FFAA de su papel protagónico en los gobiernos autoritarios y acusó de actuar "políticamente" a quienes anhelaban saber la verdad. Para más detalles ver Eabolivia, 2010 y otras noticias similares.

${ }^{11}$ Medidas como la legalización del aborto, mayores derechos civiles y políticos para las diversidades sexuales, etc.

${ }^{12}$ Por ejemplo, revisar estas noticias: Correo del Sur, 2018; Boaretto, 2015; Vaca, 2016.
} 
Finalmente, la forma en que los funcionarios de gobierno han llevado el caso de la vinculación sentimental y clientelar del presidente y otras autoridades con Gabriela Zapata, ha dejado mucho que desear en relación con el respeto hacia las mujeres, su integridad psicológica, su dignidad y su vida privada y sexual ${ }^{13}$.

\subsubsection{Persistencia de prácticas autoritarias}

Allende de la persecución de la disidencia y la violación de derechos humanos, especificada líneas arriba, fue notable la falta de crítica y autocrítica en el seno de las esferas gobiernistas y, particularmente, en la militancia del MAS. En ese marco se alejó y se censuró a los militantes que se atrevieron a cuestionar algunas decisiones de la cúpula partidista $y$, en múltiples ocasiones, los mismos dirigentes del partido han recordado a sus seguidores que dicha fuerza política no requiere de libre pensamiento y crítica, al contrario, precisaría de "soldados"14.

Adicionalmente, fue neurálgica la reacción gobiernista frente a algunas ONG críticas del régimen. El 2015 resaltó la alocución del vicepresidente del Estado acusando a algunas ONG críticas del gobierno de favorecer "intereses extranjeros" y de hacer "política", a lo que siguió una campaña de desprestigio contra esas entidades, incluyendo a los organismos internacionales que financiaban el trabajo de las instituciones ${ }^{15}$.

\subsubsection{Caudillismo y culto a la personalidad}

En los años de "proceso de cambio", hubo la tendencia en generar una especie de culto caudillista frente a la figura de Evo Morales.

Desde las esferas gubernamentales se perfiló una campaña mediática que potenció una serie de simbolismos que han rodeado la figura de Evo Morales a lo largo de su carrera política y particularmente desde que asumió el poder.
El hecho de que, imprecisamente ${ }^{16}$, se lo haya denominado el "primer presidente indígena de las Américas", posesionado en ceremonias que supuestamente reescribieron ritos y saberes precoloniales y donde varios representantes autoidentificados como de origen étnico, lo nombraron líder espiritual de los indígenas y pueblos oprimidos del mundo, reviste una carga simbólica que mantuvo a Morales como una alegoría del triunfo de la lucha descolonizadora en América Latina y del resto del planeta. Este imaginario que representó Evo Morales fue fomentado tanto por el Estado boliviano, a través de calculadas campañas mediáticas y apariciones públicas, como por las interpretaciones que refuerzan la idealización del origen étnico del mandatario, más allá de análisis serios de logros y falencias de sus gestiones de gobierno.

Como ha acontecido con otros gobiernos en la historia de Bolivia, no es extraño encontrar gigantografias con la cara de Evo Morales en cada obra o proyecto que entregó la administración pública. Ello sin contar la denominación con el nombre Morales de instituciones educativas, campañas deportivas, la escuela de abogados del Estado y hasta los jóvenes militantes del MAS, que se han articulado bajo la denominación de "Generación Evo". Es relevante recordar además la polémica que se dio por el intento de nombrar al aeropuerto de Oruro con el nombre del caudillo ${ }^{17}$.

Justamente, el carácter caudillista del MAS finalmente se constituyó en su talón de Aquiles, ya que el detonante de su caída el 2019 tuvo que ver con el empecinamiento gubernamental en repostular a Evo Morales y Álvaro García Linera a pesar de que los resultados de un referéndum cerraron la posibilidad de modificar la Constitución que en su artículo 168 indica que el presidente y el vicepresidente sólo pueden ser reelectos una sola vez de manera continua.

\footnotetext{
${ }^{13}$ Se trata del escándalo que involucraba a Evo Morales en una relación sentimental con Gabriela Zapata, que en ese momento era alta ejecutiva de la empresa china CAMC y a quien se acusó de tráfico de influencias y de beneficiarse con millonarios contratos con el Estado. Se habló de un hijo que habrían concebido, lo que fue admitido y después negado por el propio presidente. Hoy Zapata cumple una condena en la cárcel por una serie de delitos en los que se incluyen legitimación de ganancias ilícitas, asociación delictuosa, uso indebido de bienes públicos, falsedad ideológica, entre otros. No se sabe a ciencia cierta lo que ocurrió con Morales, Zapata, el supuesto hijo que tuvieron y el nepotismo que encerraban las acusaciones. Los implicados en el tema y funcionarios gubernamentales han presentado información contradictoria.

${ }^{14} \mathrm{Al}$ respecto, revisar Opinión, 2013; Los Tiempos, 2013; El Diario, 2014.

${ }^{15}$ Para un mayor análisis, revisar Gandarillas, 2016.

${ }^{16}$ Benito Juárez, presidente de México en periodos discontinuos de 1858 a 1872, fue también considerado un representante indígena.

${ }^{17}$ Recordar que este tipo de prácticas, llevadas al extremo, fueron muy comunes en las dictaduras sultanistas que, en las primeras décadas del Siglo XX, asolaron Centroamérica y El Caribe. Como indica la metáfora, estos gobiernos militares descansaban en el poder de una persona, su familia y allegados, al punto de que los bienes públicos eran administrados como propiedad privada del déspota y, las FF.AA., eran poco más que su guardia personal. En ese sentido, el culto a la personalidad de estos caudillos llegaba a los límites de lo creíble. En esta categoría de análisis están los regímenes de Trujillo en República Dominicana, la familia Somoza en Nicaragua, Batista en Cuba y Duvalier en Haití. Para mayor referencia es ilustrativo el estudio de Hartlyn (1998) sobre el régimen de Trujillo en República Dominicana.
} 
1.2 La metida de pata: el Referéndum del 21 de febrero de 2016

El Referéndum "vinculante" del 21 de febrero de 2016, preguntó a la ciudadanía si estaba de acuerdo o no con una reforma constitucional que permitiera la repostulación del binomio presidencial del MAS. Aún se pueden ver las notas de prensa y las declaraciones del presidente, vicepresidente, ministros, militantes del MAS y exponentes de los sectores sociales afines a este partido, respaldando el mecanismo que fue promovido, organizado y auspiciado por los aparatos gubernamentales. Inclusive, antes que se llevara a cabo la consulta, se percibió un marcado triunfalismo en las esferas masistas, estaban seguros de que la opción por aceptar la reforma constitucional que permitiría la repostulación de los jerarcas, ganaría por amplio margen. El propio Evo Morales declaró que esperaba un respaldo que supere el $70 \%$ de la votación: "vamos a ganar con el Sí el 21 de febrero de este año, vamos a ganar ampliamente. Eso no está en debate" (teleSUR, 2016). No esperaron que en los resultados se impusiera el "No", este desenlace no planificaron $^{18}$.

Los días siguientes al corolario, personeros de gobierno y militantes del MAS desvirtuaron los resultados de la consulta, arguyendo que se había impuesto una campaña que giró en torno a la "mentira", en relación con un escándalo de "faldas" y corrupción que involucró al presidente y que habría influido en la votación (el escándalo con Gabriela Zapata, antes mencionado). Bautizaron al 21 de febrero como el "Día de la mentira" y se impulsó un aparato propagandístico que desvirtuó al Referéndum y su desenlace. Simultáneamente, se recurrió a una serie de estratagemas y argucias retóricas y legales para insistir en la repostulación. En noviembre de 2017, el Tribunal Constitucional Plurinacional (TCP) habilitó la repostulación de la dupla del MAS, arguyendo "la aplicación preferente de convenios internacionales" (teleSUR, 2017) con relación a lo dictado en la Constitución ${ }^{19}$.

El desconocimiento del juego, que el mismo régimen promovió, generó rechazo ciudadano.
Resultó ilógico que se gastaran millones de los recursos públicos en un plebiscito para luego desconocerlo porque el resultado no le agradó al poder. Con esos argumentos, una vez conocido el resultado del Referéndum y la intención gubernamental de desechar su mandato, se generó una reacción ciudadana crítica al régimen que trascendió a los tradicionales grupos de oposición. Esa reacción se fue alimentando varios años antes, debido, en parte, a las pautas antes abordadas.

Del 2016 al 2019 se mantuvo cierta constancia en esas movilizaciones bajo la consigna "Bolivia dijo no". Estos movimientos fueron el germen de los que se articularon ante el corolario de las elecciones de octubre de 2019 y que respondieron a un carácter heterogéneo y fragmentado.

\section{La crisis de octubre-noviembre de 2019}

\subsection{Elecciones cuestionadas y renuncia presidencial}

De acuerdo con el Tribunal Supremo Electoral (TSE) los resultados de las elecciones del 20 de octubre de 2019 dieron la victoria al MAS con el 47,08 \% de los votos frente al segundo lugar, con $36,51 \%$, de Carlos Mesa de la alianza Comunidad Ciudadana (CC).

Esta diferencia del 10,57 \% otorgaba al MAS la victoria en primera vuelta con un 0,57 de margen, siendo que el sistema electoral boliviano establece que un candidato debe tener el $50 \%$ de los votos más uno o el $40 \%$ con 10 puntos de ventaja sobre el segundo puesto para ganar en primera vuelta.

Estos resultados fueron desconocidos por amplios sectores que se movilizaron denunciando un supuesto fraude electoral. Las susceptibilidades al respecto se condensaron días antes, especialmente cuando se presentaron hechos extraños eirregulares, como la suspensión de la transmisión del conteo de votos por casi 24 horas y otras denuncias que apuntaban a un proceso fraudulento. Ante eso, se iniciaron las movilizaciones primero pidiendo

\footnotetext{
${ }^{18}$ El resultado final del Referéndum dio una victoria al No con el 51,30\% de los votos frente al 48,70\% del Sí. Ver La Fuente, 2016. ${ }^{19} \mathrm{El}$ artículo 23 de la Convención Americana de Derechos Humanos indica: "Todos los ciudadanos deben gozar de los siguientes derechos y oportunidades: a. participar en la dirección de los asuntos públicos, directamente o por medio de representantes libremente elegidos; $b$. votar y ser elegidos en elecciones periódicas auténticas, realizadas por sufragio universal e igual y por voto secreto que garantice la libre expresión de la voluntad de los electores, y c. tener acceso, en condiciones generales de igualdad, a las funciones públicas de su país. 2. La ley puede reglamentar el ejercicio de los derechos y oportunidades a que se refiere el inciso anterior, exclusivamente por razones de edad, nacionalidad, residencia, idioma, instrucción, capacidad civil o mental, o condena, por juez competente, en proceso penal”. (Secretaría de Derechos Humanos y Pluralismo Cultural, 2016).
} 
la validación de la segunda vuelta, luego nuevas elecciones y finalmente la renuncia presidencial.

Después de varios días de paros y otras formas de protesta que impedian el normal desenvolvimiento de la cotidianidad laboral, el gobierno respondió convocando a una auditoría "vinculante" del proceso electoral por parte de la OEA. El domingo 10 de noviembre salieron los resultados de la auditoría, indicando que hubo irregularidades y recomendando nuevas elecciones. Con ello, las movilizaciones crecieron, lo que incluyó un motín policial en varias regiones, la "sugerencia" de las FF.AA. que solicitaban la dimisión presidencial y una petición similar de la COB y otros organismos obreros y campesinos.

En conclusión, Evo Morales y el vicepresidente Álvaro García Linera renunciaron, siguiendo autoridades y cabecillas del MAS, como Adriana Salvatierra y Rubén Medinacelli, presidenta y Primer Vicepresidente de la Cámara de Senadores, respectivamente. Ello allanó el camino a la opositora Jeanine Áñez por el Movimiento Demócrata Social (MDS) (que ocupaba la cartera de Segunda Vicepresidente de la Cámara de Senadores) para hacerse con la presidencia de Bolivia bajo el argumento de sucesión constitucional "ipso facto" ${ }^{20}$.

Añez asumió el mandato el 12 de noviembre de 2019. Posteriormente, el Congreso boliviano aprobó anular las elecciones de octubre para posibilitar la realización de nuevos comicios.

\section{2 "Pititas": heterogeneidad en las movilizaciones contra los resultados eleccionarios}

Tiempo antes del desenlace del 2019, ante la concentración del poder que sobrellevaba la hegemonía partidaria del MAS y el raquitismo de una oposición partidaria fragmentada, se dio el fenómeno del surgimiento de iniciativas ciudadanas a título de "Colectivos", "Plataformas", "Movimientos", etc.Algunas de estas manifestaciones tienen un historial de lucha de larga data, otra es la experiencia de nuevas propuestas que se han multiplicado en los últimos años. En todos los casos, estos organismos se han fortalecido y han ampliado su alcance gracias a las redes sociales, mecanismos comunicativos relativamente libres, de fácil y masivo acceso y que difícilmente pueden ser subyugados por intereses políticos, corporativos y otros, a diferencia de los medios de comunicación tradicionales.

Estas organizaciones colectivas enunciaron diversidad de proyectos, propuestas, discursos, fines, ideologías, mecanismos de acción, etc. Las hay feministas, ambientalistas, defensoras de derechos de las diversidades sexuales y grupos étnicos, temáticas, culturales, reivindicativas de contenidos coyunturales, ligadas a proyectos político-partidarios e intereses gremiales. Cabe recalcar que parte de estos movimientos también tienden a ser funcionalizados, ya sea por el mismo MAS o por una oposición partidaria moribunda que encontró nuevos bríos en estas entidades $^{21}$.

A partir de algunas de estas formas de organización civil, se nutrieron las protestas contra los gobiernos del MAS por el desconocimiento de los resultados del Referéndum de febrero de 2016 y que continuaron en apronte hasta que el descontento social estalló en octubre-noviembre de 2019.

Las movilizaciones de esos agitados meses se caracterizaron por convocar gran cantidad de personas, pero también porque los participantes eran grupos heterogéneos y fragmentados que no compartían ideologías y menos una agenda o programa político único más allá del rechazo al gobierno del MAS y a las elecciones de octubre. Era evidente que, si estos grupos se enfrentaban a otras temáticas, hubieran exteriorizado posiciones radicalmente distintas y contrarias dado que en sus filas había feministas, ambientalistas, anarquistas, de la izquierda clásica más allá del MAS, pero también hubo representación de sectores conservadores y de la élite tradicional desplazada del poder por el MAS, algunos vinculados a la oposición partidaria.

Otra característica de los levantamientos de fines del 2019 fue una convocatoria que atrajo a gran cantidad de jóvenes "millennials" y hasta "centennials", especialmente de clases medias, que recurrieron al Whastapp para organizarse y ejecutar los bloqueos, ello principalmente en las urbes.

Los bloqueos fueron por demás pintorescos, se utilizaron una serie objetos domésticos como juguetes, insumos de cocina, mueblería y hasta

${ }^{20}$ Esta cadena de renuncias de las autoridades masistas genera dudas sobre a qué objetivo respondían. ¿Se generaron las renuncias por la presión de los aparatos represivos y los sectores movilizados? ¿Se esperaba que estas dimisiones explosionaran en un apoyo popular masivo que volcara la tortilla a favor del presidente y máximas autoridades? ¿Se buscaba consolidar el alegato de que se gestaba un golpe de Estado?

${ }^{21}$ Ver Guardia, Marcelo, Zegada María Teresa, 2019. Estremadoiro, 2018. 
pitas o cuerdas. Por eso, el entonces presidente Morales, declaró con sarcasmo:

"Me he sorprendido, ahora dos, tres personas (están) amarrando 'pititas', poniendo 'llantitas'. ¿Qué paro es ese (...)? Soy capaz de dar talleres, seminario de cómo se hacen las marchas a ellos, para que aprendan" 22 .

Tomando con ironía las palabras de Morales los propios manifestantes denominaron a su movimiento como "revolución de las pititas".

No obstante, allende lo peculiar, amplio y heterogéneo de estas movilizaciones, los sectores conservadores, anacrónicos y vinculados a la élite y partidos tradicionales opositores del oficialismo masista, fueron los que terminaron tomando no solamente el nuevo gobierno, sino la vanguardia ideológica y discursiva de las movilizaciones de octubre-noviembre de 2019.

\section{3. ¿El retorno del falangismo?}

\subsection{Banderas en las espaldas, rezos en las esquinas}

Una característica de las manifestaciones de fines del 2019, a medida que estallaba una polarización violenta entre quienes pugnaban por el poder, fue que se hizo intensiva la interpelación religiosa y el estridente nacionalismo militar como parte importante de los discursos y simbolismos de quienes se alzaron contra el gobierno del MAS y los resultados de las elecciones de octubre.

Al son de los típicos himnos y marchas militares, era común ver a los manifestantes ataviados en las espaldas con la tricolor boliviana como alusión constante a la "defensa de la patria" o la "República de Bolivia" y en desconocimiento del Estado Plurinacional como si este fuera un logro tendencioso y exclusivamente "masista".

Así, se articularon fuertes maniqueísmos en los que todos los males de la historia de Bolivia se debían única y exclusivamente a los gobiernos del MAS, calificados, imprecisamente, como "dictadura". Estas expresiones, en no pocas ocasiones, conllevaban tintes racistas contra el origen étnico de Morales y otros militantes del MAS. Al otro lado del espectro, los militantes del MAS también enunciaron dicotomías similares e igual de inexactas, estereotipadas, violentas y estridentes, reduciendo lo que acontecía a un quiebre de "indios versus blancos", "clases populares versus clases medias", "pobres versus ricos", "izquierda versus derecha”.

Juntamente, la interpelación religiosa cristiana, y específicamente católica, se hizo notoriamente presente en el discurso político. No faltaban en los cabildos rezos y oraciones contra lo que denominaron (erradamente) un "gobierno ateo" 23 . Al mismo tiempo, la Iglesia Católica, en cierta medida desplazada del poder desde la asunción del Estado laico, volvió a exhibir protagonismo político. Por otra parte, no escasearon las expresiones conservadoras y ultramilitaristas que pasaron de la marginalidad a tomar la palestra. Grupos antifeministas, contra las diversidades sexuales y hasta enunciaciones racistas y clasistas que se creyeron superadas, salieron a la luz.

Es importante recordar que este tipo de pautas ideológicas no fueron nuevas en Bolivia. Durante las dictaduras de la década del 60 y del 70, principalmente en la dictadura de Banzer, se posicionó el eje ideológico del falangismo, emulación boliviana del franquismo español, que antes era un pensamiento minoritario y que se constituyó como significativo en esa época. Los imaginarios de esta tendencia albergaban la interpelación religiosa, el chovinismo militarista, el anticomunismo maniqueo y un profundo conservadurismo ${ }^{24}$. Luego de la transición democrática estos patrones volvieron a la marginalidad hasta hoy, que parecen haber despertado con nuevos bríos en el contexto descrito.

\subsection{Grupos irregulares y ola de violencia}

El referente más claro del militarismo conservador que tomó protagonismo fue la constitución de grupos irregulares con tufillo paramilitar. Es el caso de la Resistencia Juvenil Cochala (RJC), primero con sede en la ciudad de Cochabamba y después con intenciones de extenderse al resto del país.

Esta agrupación que se particularizó por transportarse en motocicletas (por lo que también se los denominaron "motoqueros") y por portar

\footnotetext{
${ }^{22}$ Citado en Chambi, 2019.

${ }^{23} \mathrm{Si}$ bien uno de los avances de la nueva Constitución boliviana aprobada y promovida por los gobiernos del MAS fue el Estado laico, ello no implicó que estos regímenes se constituyeran como "ateos". Al contrario, fueron sonados los acuerdos del MAS con evangelistas y, en más de una ocasión, los propios cabecillas del MAS hacían espectáculos mediáticos "rezando" en iglesias católicas con el fin de ganar la simpatía de sectores que continúan en ese espectro. Eso sí, cabe destacar que la relación de los gobiernos del MAS con la Iglesia Católica fue tirante y de conflicto.

${ }^{24}$ Para ahondar en las características mencionadas de la dictadura banzerista, ver la investigación de Estremadoiro, 2008.
} 
armas caseras, fue la cara más violenta de las movilizaciones de las "pititas”. Ante el amotinamiento de la policía, se atribuyeron labores propias de los aparatos represivos institucionalizados, como "vigilancia” y "protección" de los movilizados ante la reacción de grupos afines al MAS.

Desempeñaron varios hechos de violencia y violación de los derechos humanos, como la agresión a la alcaldesa por el MAS del municipio de Vinto en Cochabamba, quien fue interceptada, echada con pintura roja, obligada a caminar de rodillas y a quien le cortaron los cabellos ${ }^{25}$. Otro caso fue el intento de asesinato de un periodista, quien recibió tres puñaladas a la salida de una discoteca, perpetrado por un miembro que fue denunciado como parte de $\mathrm{RJC}^{26}$. De igual forma, fue sonada la expulsión de mujeres de pollera y otras personas que se encontraban en la plazuela de Cala $\mathrm{Cala}^{27}$, centro de reuniones de la RJC pero que no dejaba de ser espacio público, acto calificado como racista, arbitrario y discriminador. Asimismo, y ya en el Gobierno transitorio, frente a anuncios de movilizaciones por parte de militantes del MAS en el marco del aniversario del Estado Plurinacional el 22 de enero de 2020, RJC amenazó con reactivarse y "responder" aunque para ese entonces ya estaban en funcionamiento los aparatos represivos institucionalizados. Es relevante rememorar que, durante los conflictos tras la salida de Evo Morales, este grupo "apoyó" muchas veces a la policía y FF.AA. contra los bandos afines al MAS.

Se destaca, sin embargo, que luego de la dimisión de las autoridades masistas y la asunción del régimen transitorio, hubo una ola de violencia que involucró tanto a militantes del MAS como a los grupos que estaban contra ese partido y el gobierno depuesto. Esas luctuosas jornadas, incluyeron linchamiento de personas, quemas de bienes y espacios públicos, incendios de casas de periodistas y representantes políticos de ambos bandos y amenazas de guerra civil. Bajo esa coyuntura, fue asesinado un miembro de RJC por una turba y otro amarrado y golpeado ${ }^{28}$.

\subsection{Apuntes sobre el Gobierno transitorio}

Bastante simbólico el hecho de que el Gobierno transitorio haya asumido su mandato con una Biblia en mano. Poco tiempo antes, el líder cívico cruceño Luis Fernando Camacho, uno de los actores más visibles que encarnaban los levantamientos de finales del 2019, había prometido que llevaría una carta de renuncia de Evo Morales y una Biblia a las infraestructuras del poder político para que "Dios vuelva al palacio"29. De esa manera, se vio a Camacho junto a la presidenta transitoria y otras autoridades del nuevo régimen con el famoso "libro sagrado" al inaugurar su mandato.

Este distintivo suceso fue continuado por otros similares durante esa gestión gobiernista. No sólo en varias alocuciones públicas la presidenta y altas autoridades enunciaban a Dios y a los postulados cristianos constantemente, sino que llegaron a ejecutarse acciones públicas como contratar helicópteros para rociar con agua bendita algunas ciudades ante la pandemia de la COVID-19 y no faltaron declaraciones gubernamentales que aseguraron que el "ayuno y oración" vencerían al virus $^{30}$. Llama la atención que, ante la prohibición de reuniones masivas para evitar los contagios de esa enfermedad, solamente se tuviera tolerancia con las celebraciones religiosas, aunque, ante las críticas, se retrocedió con la medida ${ }^{31}$.

Otro rasgo del régimen es la confirmación y continuidad del militarismo. Aparte de asignar presupuesto adicional destinado al equipamiento de las FF.AA. ${ }^{32}$, aprobó un polémico Decreto en el que eximía de responsabilidad penal a militares que participaran de operativos de "restauración del público" en el marco de la crisis política que rodeaba a su administración. La misma presidenta declaraba que: "el Gobierno tuvo que asumir la medida porque enfrentó acciones violentas que nunca antes habíamos visto en nuestra historia y nunca quisiéramos verlas de nuevo" (Citado en Los Tiempos, 28 de noviembre de 2019). Posteriormente, el Decreto fue abrogado debido a que "esta determinación ha sido tomada en consideración a que gracias a Dios y a la comprensión de todos

${ }^{25}$ Revisar: Quisbert, 2019. Otras versiones realzan que dichos vejámenes a la alcaldesa fueron en "represalia" por el asesinato del joven Limbert Guzmán Vásquez, acaecido supuestamente en manos de grupos afines al MAS y a la autoridad. Ver: Los Tiempos, 2019.

26. Ver Opinión, 2020.

${ }^{27}$ Revisar Los Tiempos, 2020

${ }^{28}$ Ver Los Tiempos, 2019.

${ }^{29}$ Citado en France24, 2019.

${ }^{30}$ Por ejemplo, revisar Agencia EFE, 2020

${ }^{31}$ Ver Corz, 2020.

${ }^{32}$ Ver Opinión, 2019. 
los sectores del país, hemos logrado la ansiada pacificación" (Idem). Otra medida que fortaleció a los aparatos represivos fue el incremento de sueldos y otros beneficios a favor de la policía ${ }^{33}$.

La "pacificación” incluyó incidentes de cruda represión y la denuncia de violaciones a los derechos humanos como lo ocurrido en las localidades de Senkata y Sacaba, donde las fuerzas del orden se enfrentaron con militantes del MAS en condiciones sumamente desiguales y violentas para estos últimos. Estos episodios fueron catalogados como masacres por la Comisión Interamericana de Derechos Humanos (CIDH). Fallecieron más de una treintena de personas ${ }^{34}$.

Por otra parte, en apenas meses de gobierno salieron a la luz escandalosos casos de corrupción. El más lamentable fue un supuesto sobreprecio en la compra de respiradores en un delicado contexto de pandemia ${ }^{35}$.

Es necesario subrayar que por la pandemia de la COVID-19, las elecciones programadas para mayo de 2020 tuvieron que ser suspendidas hasta septiembre pero, de todas maneras, otras medidas del Gobierno transitorio son cuestionadas y de dudosa legitimidad, porque se dilucidan atribuciones decisorias que no corresponden a un carácter de transición.

Es el caso de la autorización para establecer mecanismos abreviados para la evaluación de semillas transgénicas en Bolivia ${ }^{36}$, lo que denota la alianza del régimen con la plutocracia agroindustrial, y del cierre de los Ministerios del Culturas y Deportes y Comunicación que serán fusionados a los Ministerios de Educación y de la Presidencia, respectivamente ${ }^{37}$.

Si bien todavía es poco tiempo el que este régimen está gobernando para realizar una evaluación precisa y objetiva, estos hechos dan algunas luces respecto a su tendencia ideológica y hacia dónde se encamina.

\section{A manera de conclusión}

Un doloroso aspecto a acentuar es que si revisamos la historia política de Bolivia, encontraremos que gobiernos radicalmente distintos, en ideología, posición política, diferencias de coyuntura histórica, en cuanto a la praxis del manejo de la gestión pública, conllevan atributos escalofriantemente similares: tendencia a la concentración del poder $\mathrm{y}$ al centralismo, autoritarismo y abuso de poder, corrupción, prácticas clientelistas y nepotistas, militarismo, deficiente planificación pública, revanchismo, extractivismo, discursos y simbolismos vacíos que distan de la práctica real.

Aquello podemos evidenciarlo si comparamos los salientes gobiernos del MAS con el actual régimen transitorio. Por ello, no está demás compartir una breve reflexión que hacía Alberto Gutiérrez, historiador y diplomático del Siglo XIX, pero cuya acepción puede aplicarse para describir cierta dinámica de los gobiernos bolivianos que se repite inclusive en el Siglo XXI:

Hay otro factor que crea esas contradicciones, que el historiador se encuentra en el deber de investigar en sus verdaderos orígenes. Es la educación de los políticos en Bolivia, la tendencia a la adulación y el servilismo, la predisposición enfermiza que forma bandas voluntarias de sicarios y esbirros. La lisonja palaciega que malea y pervierte los mejores caracteres... (Gutiérrez, 1976, p. 216).

Cabe preguntarse si el poder (y la obsesiva y mezquina pugna que encierra) verdaderamente envilece a las instituciones y corrompe al ser humano y, más todavía, cuando se perfila el intento constante de concentrarlo, monopolizarlo, tomarlo como un feudo y abusar de él. ¿O qué otra cosa le sucede a la turbulenta Bolivia?

\section{Referencias}

Agencia EFE. (27 de abril de 2020). Áñez pide una jornada de "ayuno y oración" para vencer la pandemia en Bolivia. Agencia EFE Recuperado de https:// www.efe.com/efe/america/sociedad/anez-pide-unajornada-de-ayuno-y-oracion-para-vencer-la-pandemiaen-bolivia/20000013-4232441

Almaraz, A., Fernández, O., Fernández, R., Komadina, J., Mamani, P., Olivera, O., Regalsky, P., Soto, G. (2012) La MAScarada del poder. Buenos Aires, Argentina: Ediciones Herramienta

Antezana, L. H. (1983). Sistema y proceso ideológico en

\footnotetext{
${ }^{33}$ Ver Correo del Sur, 2020.

${ }^{34}$ Más detalles en Correo del sur, 2019.

${ }^{35}$ Detalles en Miranda, 2020.

${ }^{36}$ Revisar Los Tiempos, 2020. Este tipo de política no es nueva, en la década de 1990 se inició con la introducción de soya transgénica y siguió con los gobiernos sucesivos, incluidos los del MAS. Ver Somos Sur, 2011 y Página Siete, 2020.

${ }^{37}$ Detalles en Opinión, 2020
} 
Bolivia 1935-1979. En Zavaleta Mercado, R. (Comp.). Bolivia Hoy. México: Siglo XXI.

BBC. (2013). Bolivia conmocionada por video de una supuesta violación. BBC News. Recuperado de https://www.bbc.com/mundo/noticias/2013/01/130118 bolivia video supuesta violacion legislador irm

Boaretto, R. (18 de noviembre de 2015). Evo Morales: "No quiero pensar que es lesbiana, compañera ministra". La izquierda diario. Recuperado de http://www.laizquierdadiario.com.bo/Evo-Morales-Noquiero-pensar-que-es-lesbiana-companera-ministra

Carrasco, G. (15 de octubre de 2019). Los incendios de la Chiquitanía tendrían impacto en el voto de los bolivianos. CNN español. Recuperado de https:// cnnespanol.cnn.com/2019/10/15/los-incendios-de-lachiquitania-tendria-impacto-en-el-voto-de-los-bolivianos/

Chambi, F. (30 de diciembre de 2019). Valor y rebeldía: la "pitita" que despertó a otra Bolivia. Los Tiempos. Recuperado de https://www.lostiempos.com/actualidad/ pais/20191230/valor-rebeldia-pitita-que-desperto-otrabolivia

Correo del Sur. (3 de marzo de 2018). Llueven críticas contra Morales por su chiste. Correo del Sur. Recuperado de https://correodelsur.com/politica/20180303 lluevencriticas-contra-morales-por-su-chiste.html

Correo del Sur. (11 de diciembre de 2019). CIDH habla de "masacres" en Sacaba y Senkata. Correo del Sur. Recuperado de https://correodelsur.com/ politica/20191211_cidh-habla-de-masacres-en-sacaba-ysenkata.html

Correo del Sur. (2 de abril de 2020). Incrementan los salarios de los policías y ahora reciben entre 450 y 470 bolivianos más. Correo del Sur. Recuperado de $\quad$ https://correodelsur.com/seguridad/20200402 incrementan-los-salarios-de-los-policias-y-ahora-recibenentre-450-y-470-bolivianos-mas.html

Corz, C. (5 de junio de 2020). El Gobierno retrocede y suspende actos religiosos con 30\% de aforo en la cuarentena. La Razón. Recuperado de https:// www.la-razon.com/sociedad/2020/06/05/el-gobiernoretrocede-y-suspende-actos-religiosos-con-30-de-aforo-enla-cuarentena/

Eabolivia. (18 de febrero de 2010). Asofamd: Ha llegado la hora de decir la verdad sobre las dictaduras en Bolivia. Eabolivia. Recuperado de https://www. la-razon.com/? url=\%2Fnacional\%2FAcusan-FFAAcumplir-orden-Suprema_0_1173482652.html

ElDiario. (8dejunio de 2014). ElMAS no quiere librepensantes como postulantes. El Diario Recuperado de http:// www.eldiario.net/noticias/2014/2014_06/nt140608/politica. php?n=76\&-el-mas-no-quiere-librepensantes-comopostulantes

El País. (31 de septiembre 1990). Vargas Llosa: "México es la dictadura perfecta”. El País. Recuperado de: https:/l elpais.com/diario/1990/09/01/cultura/652140001_850215.html.
El País. (24 de febrero de 2016). Bolivia le dice no a la intención de Evo Morales de buscar otra reelección. El País. Recuperado de https://elpais.com/ internacional/2016/02/24/actualidad/1456274986_514912. $\underline{\mathrm{html}}$

Estremadoiro, Rocío. (2008). Algunas dimensiones de análisis a partir de la matriz ideológica de la dictadura de Banzer en Bolivia. (Tesis de Máster en Estudios Latinoamericanos). Universidad de Salamanca, Salamanca, España.

Estremadoiro, Rocío. (2018). Movimientos 21 F. Hegemonía partidaria y contrapesos. Revista Cuarto Intermedio, No. 120 (pp. 46-57).

France24. (10 de noviembre de 2019). La Biblia se cuela en la disputa política en Bolivia. France24. Recuperado de https://www.france24. com/es/20191110-la-biblia-se-cuela-en-la-disputapol\%C3\%ADtica-en-bolivia

Gandarillas, M. (2016). La libertad de asociación en uno de los países más democráticos (y extractivistas) del mundo. Petropress. Centro de Documentación e Información de Bolivia. Recuperado de http://www.cedib.org/ publicaciones/la-libertad-de-asociacion-en-uno-de-lospaises-mas-democraticos-y-extractivistas-del-mundopetropress-35-3-16/

Guardia, M., Zegada, M. T. (2019). La vida política del meme, interacciones digitales en Facebook en una coyuntura crítica. Cochabamba, Bolivia: Plural.

Gutiérrez, A. (1976). La guerra de 1879. Nuevos esclarecimientos. La Paz, Bolivia: Ediciones Populares Camarlingui.

Hartlyn, J. (1998). The Struggle for Democratic Politics in the Dominican Republic. Londres: The University of North Carolina Press.

Knight, A. (2011). La revolución mexicana. México, Fondo de Cultura Económica. DOI: https://doi. org/10.2307/j.ctv47wf39.19

Knight, A. (2015). La revolución cósmica. Utopías, regiones y resultados. México 1910-1940. México, Fondo de Cultura Económica.

Krauze, E. (2012). La dictadura perfecta. Letras libres. Recuperado de https://www.letraslibres.com/mexicoespana/la-dictadura-perfecta.

López, E. (7 de diciembre de 2017). Caso Fondo Indígena sin acusación formal a casi 3 años de la denuncia. Los Tiempos. Recuperado de https:// www.lostiempos.com/actualidad/economia/20171207/ caso-fondo-indigena-acusacion-formal-casi-3-anosdenuncia

Los Tiempos. (10 de enero de 2013). García Linera les dice a los masistas que si son libres pensantes pueden irse. Los Tiempos. Recuperado de https:// www.lostiempos.com/actualidad/nacional/20130110/ 
garcia-linera-les-dice-masistas-que-si-son-librespensantes-pueden-irse

Los Tiempos. (28 de noviembre de 2019). Añez abroga el Decreto 4078 que eximía de responsabilidad penal a FFAA. Los Tiempos Recuperado de https://www.lostiempos.com/actualidad/pais/20191128/ anez-abroga-decreto-4078-que-eximia-responsabilidadpenal-ffaa

Los Tiempos. (8 de noviembre de 2019). Abren dos investigaciones y Alcaldesa de Vinto se repone. Los Tiempos. Recuperado de https://www. lostiempos.com/actualidad/cochabamba/20191108/ abren-dos-investigaciones-alcaldesa-vinto-se-repone

Los Tiempos. (13 de noviembre de 2019). Fallece joven de la Resistencia Cochala tras ser golpeado en la zona sur, otro miembro se encuentra internado. Los Tiempos. Recuperado de https://www. lostiempos.com/actualidad/cochabamba/20191113/ fallece-joven-resistencia-cochala-ser-golpeado-zona-surotro-miembro

Los Tiempos. (17 de enero de 2020). Resistencia desaloja bruscamente aun grupo de personas de la plazuela Cala Cala. Los Tiempos. Recuperado de https://www. lostiempos.com/actualidad/cochabamba/20200117/ resistencia-desaloja-bruscamente-grupo-personasplazuela-cala-cala

Los Tiempos. (8 de mayo de 2020). Añez aprueba decreto para abreviar procedimientos de evaluación de semillas transgénicas de maíz, trigo y soya. Los Tiempos. Recuperado de https://www.lostiempos. com/actualidad/pais/20200508/anez-aprueba-decretoabreviar-procedimientos-evaluacion-semillas

Magaloni, B. (2006). Voting for Autocracy: Hegemonic Party Survival and its Demise in Mexico. Cambridge, Reino Unido: Cambridge University Press. DOI: https://doi.org/10.1017/CBO9780511510274

Medrano, E. (6 de abril de 2015). Caso Terrorismo I dejó cabos sueltos. Ejú TV. Recuperado de https:// eju.tv/2015/04/el-caso-rzsa-terrorismo-dej-al-menoscuatro-cabos-sueltos/

Miranda, B. (20 de mayo de 2020) Coronavirus en Bolivia: un escándalo por la compra de respiradores provoca la destitución del ministro de Salud. BBC News. Recuperado de https://www.bbc.com/ mundo/noticias-52747870

Mouffe, C. (1986). Hegemonía e ideología en Gramsci. Teoría 5

Opinión. (15 de julio de 2013). MAS inicia represalias contra "librepensantes". Opinión. Recuperado de https://www.opinion.com.bo/articulo/el-pais/mas-iniciarepresalias-librepensantes/20130615013600474049.html

Opinión. (18 de noviembre de 2019). Gobierno aprueba decreto que transfiere Bs 34,7 millones para las FFAA. Opinión. Recuperado de https://www.opinion.com.bo/articulo/pais/gobierno- anez-aprueba-decreto-transfiere-bs-347-millonesffaa/20191118211652737418.html

Opinión. (2 de febrero de 2020). Periodista es apuñalado y acusa a miembro de la Resistencia. Opinión. Recuperado de https://www.opinion.com.bo/articulo/ policial/periodista-es-apunalado-acusa-miembro-resiste ncia/20200202123827749032.html

Opinión. (5 de junio de 2020). Áñez cierra tres ministerios y dos embajadas; hay rechazo y críticas. Opinión. Recuperado de https://www.opinion.com. bo/articulo/pais/anez-cierra-ministerios-embajadasrechazo-criticas/20200605005548771210.html

Página Siete. (13 de octubre de 2013). Fallece José María Bakovic, ex presidente de Caminos. Página Siete Recuperado de http://www.paginasiete. bo/sociedad/2013/10/13/fallece-jose-maria-bakovicexpresidente-caminos-3032.html

Página Siete. (17 de diciembre de 2019). Incendio de la Chiquitanía entre los grandes desastres de 2019. Página Siete. Recuperado de https://www.paginasiete. bo/miradas/2019/12/17/incendio-de-la-chiquitania-entrelos-grandes-desastres-de-2019-240614.html

Página Siete. (10 de mayo de 2020). En 2011 Evo legalizó transgénicos y ahora acusa al Gobierno de que "nos mata" con transgénicos. Página Siete. Recuperado de https://www.paginasiete.bo/ economia/2020/5/10/en-2011-evo-legalizo-transgenicosahora-acusa-al-gobierno-de-que-nos-mata-contransgenicos-255107.html

Pomacahua, P. (2 de junio de 2017). Condenan y destituyen a Gualberto Cusi. Página Siete. Recuperado de https://www.paginasiete.bo/nacional/2017/6/2/ condenan-destituyen-gualberto-cusi-139776.html

Quisbert, C. (7 de noviembre de 2019). Intentan linchar a la Alcaldesa del MAS y queman sede edil en Vinto. Página Siete. Recuperado de https://www. paginasiete.bo/nacional/2019/11/7/intentan-linchar-laalcaldesa-del-mas-queman-sede-edil-en-vinto-236654. $\underline{\mathrm{html}}$

Rivera, S. (2015). Mito y desarrollo en Bolivia. El giro colonial del gobierno del MAS. La Paz, Bolivia: Piedra Rota.

Secretaría de Derechos Humanos y Pluralismo Cultural. (2016). Convención Americana sobre Derechos Humanos. Argentina: De bolsillo. Recuperado de $\quad$ https://www.argentina.gob.ar/sites/default/files/ derechoshumanos_publicaciones_colecciondebolsillo_10 convencion americana ddhh.pdf

Somos Sur (2011). Los transgénicos en Bolivia: Algo de historia. Recuperado de https://www.somossur.net/ bolivia/economia/agro-y-seguridad-alimentaria/710-lostransgenicos-en-bolivia-algo-de-historia.html

TeleSUR. (2 de enero de 2016). Evo Morales aspira 70\% de apoyo en referendo. TeleSUR. Recuperado de https://www.telesurtv.net/multimedia/Evo-Morales- 
aspira-70-de-apoyo-en-referendo-20160102-0016.html

TeleSUR. (28 noviembre 2017). Tribunal Constitucional habilita la repostulación de Evo Morales para 2019. TeleSUR. Recuperado de https://www. telesurtv.net/news/Tribunal-habilita-la-repostulacionde-Evo-Morales-para-2019-20171128-0047.html.

Vaca, M. (1 de marzo de 2016). El machismo le pasa factura a Evo Morales. Univisión. Recuperado de http://www.univision.com/noticias/corrupcion/elmachismo-le-pasa-factura-a-evo-morales 